\title{
openaccess
}

\section{Step away from the CAD station: A hands-on and immersive approach to second year teaching of Mechanical Engineering design}

\author{
Peter Dorrington ${ }^{1}$ 이 0000-0002-9145-8492, Will Harrison ${ }^{1}$ (ㄷ) 0000-0002-0380-7075, \\ Helen Brown ${ }^{2} \odot$ 0000-0001-9547-2470, Marc Holmes ${ }^{1} \odot 0$ 0000-0002-8206-5451 and \\ Rhian Kerton ${ }^{1}$ (1) 0000-0001-5859-9747 \\ ${ }^{1}$ College of Engineering, Swansea University, ${ }^{2}$ Bath University
}

The purpose of this paper is to present a new methodology to enhance creativity within the context of learning and teaching in an engineering design module in the College of Engineering at Swansea University. The challenges to introducing creativity into an engineering undergraduate course are explored, with the main intervention-Virtual Reality for concept development-investigated through pre- and post-intervention surveys, student interviews and a focus group. Additional interventions to enhance creativity are discussed and future improvements to module design put forward.

\section{Introduction}

\section{The need for a teaching intervention}

In an increasingly competitive market for graduate employees, it is important that students are equipped with the necessary skills for success in the workplace. One such skills gap identified by the Professional Engineering Institution responsible for external accreditation-The Institute for Mechanical Engineers (IMechE, 2019)-of Swansea University's Mechanical Engineering Course, was the need to see more evidence of creativity in design modules. "Creative problem-solving is valuable at any stage in the design process, but it is of critical importance in the conceptual design stage" according to Robertson and Radcliff (2009, p. 136).

A recent article by Morin, Robert, and Gabora (2018, p. 150) describes how engineers are often asked to be innovative in their work, which in turn "implies that they must possess and demonstrate creative abilities".
The concept of "creativity" changes depending on an individual's viewpoint: "As with other domains, most notably science, students ... enter empirical examinations of creativity with robust and resilient prior-conceptions-many of which impede the study and enhancement of creativity" (Plucker, Beghetto, \& Dow, 2004, p. 85). The current first author observed one engineering student in a recent virtual reality creativity session who mused: "we are not trying to become artists", illustrating nicely, the prior conceptions that can provide early obstacles to developing creativity in education. Plucker et al. (2004, p. 86) describe one myth being the preconceived notion that creativity is a "fuzzy" and "soft" construct, and how in the extreme, a creative person might be seen "as a barefooted hippie running around a commune while rubbing crystals on his forehead". Although rather extreme, this does highlight how the area of creativity may be viewed as "soft" skills through the

\section{Correspondence}

Peter Dorrington (p.j.dorrington@swansea.ac.uk)

doi: 10.1255/vrar2018.ch3

Citation: P. Dorrington, W. Harrison, H. Brown, M. Holmes and R Kerton, Step away from the CAD station: A hands-on and immersive approach to second year teaching of Mechanical Engineering design", in Proceedings of the Virtual and Augmented Reality in Higher Education Conference 2018, Ed by J. Hudson and R. Kerton. IM Publications Open, Chichester, pp. 15-31 (2019). https://doi.org/10.1255/vrar2018.ch3

\section{c) 2019 The Authors}

This licence permits you to use, share, copy and redistribute the paper in any medium or any format provided that a full citation to the original paper is given.

Print ISBN: 978-1-906715-30-4 Online ISBN: 978-1-906715-28-1 
lens of a STEM (Science, Technology, Engineering and Maths) practitioner or student, who comes to the area with preconceived ideas about the utility of creativity. Despite these negative conceptualisations of creativity within STEM, Amabile highlights how organisational innovation relies upon the "successful implementation of creative ideas within an organisation" (1988, p. 126). Creativity, when nurtured and managed well, is a central component to the innovative success of any organisation interested in developing new or useful products or ideas (Amabile, 1988). Plucker et al. (2004) provide an in-depth exploration of these pitfalls and myths in the educational psychology literature, culminating in the following definition of "creativity":

"Creativity is the interaction among aptitude, process, and environment by which an individual or group produces a perceptible product that is both novel and useful as defined within a social context."

(ibid.)

Joao and Silva provide an insight into developing the thinking skills of engineering students, in particular Chemical Engineering students. They describe how "most of the chemical engineering students are not natural creative thinkers, as most of us, and so some idea generation methods are required to change the usual thinking process and to stimulate creative thinking" (2014, p. 43). This is where the term "aptitude" is important in the above definition, as it refers to a dynamic skill-set that one can develop through experience, learning and training; that is, supporting the premise that we can train our undergraduates to improve their creativity. How creativity is encouraged and incorporated into engineering curricula remains centrally important to providing an enriching environment for students to develop their creative skill set. For example, a recent large-scale meta-review of US and Spanish engineering students' experiences of creativity in education (total sample of 196 students), concluded there is a pervasive perception among students that "creativity" is largely missing from engineering education (EdwardsSchachter, Garcia-Granero, Sanchez-Barrioluengo, Quesada-Pineda, \& Amara, 2015).

The question for numerous academics such as Joao and Silva (2014) and Morin et al. (2018), along with the authors of this paper, is therefore, how to train future engineers to be more creative? Particularly "...given the challenges and expectations facing teachers, creativity is often seen as leisure in teaching practice. While creativity is considered a core 21st century thinking skill, many people are hesitant to self- identify as 'creative', or are uncomfortable with intellectual risk-taking and open-endedness" (Henriksen, Richardson, \& Mehta, 2017, p. 140). Moreover, introducing creative problem-solving activities and challenging the traditional engineering pedagogical approaches-such as lecturebased didactic teaching assessed through end of module exams-adds to this challenge. Engineering design combines aspects of analytical skills combined with creativity and therefore teaching the subject combines structured and unstructured learning processes, a whole brain learning process described by (Herrmann, 1991).

\section{Introducing creative problem-solving into an engineering undergraduate module}

This research is based on a pedagogic intervention in the Mechanical Engineering portfolio at Swansea University: the development of a second year undergraduate Mechanical Engineering design module to enable engineering students to be more creative. Previously, Mechanical Engineering design projects at Swansea University (SU) focused around a design brief; students were placed into groups of six, and then through a series of taught didactic content delivery and supported PC Labs (for Computer Aided Design; CAD), they developed their engineering designs. In itself this has been successful, evidenced through improved module feedback scores; however, with the highlighted creativity gap, in 2017 , along with Swansea University's strategy for enhanced learning and teaching, an opportunity arose to reassess the module learning outcomes and module construction to develop the students' creative skills gap highlighted by the accrediting body.

Cropley asserts that creativity is like an iceberg, in that the end result is often only seen, say $10 \%$, and the other $90 \%$ is a "complex interplay of personal properties, feelings, motivation, cognitive processes, organizational and social factors that deliver the visible product" (Cropley, 2015, p. xviii). The premise being that in order to achieve the best possible result from creative engineering efforts, there must be an understanding of both the tip of the iceberg and everything that lies beneath.

\section{Observed barriers to creativity for undergraduate engineering students?}

In the combined experience of the authors, engineering students typically develop their concept designs through a limited number of basic concept sketches (if any), followed by a reliance on Computer Aided Design 
(CAD). Kuksa and Childs capture how this screen-based interaction is now commonplace:

"We interact with our 'smart' TVs and 'smart' phones on a daily basis, we talk to our 'smart' sat navs and we exercise with 'smart' virtual trainers. Interestingly, all these interactions happen via a screen, an interface or, as some researchers might argue, a barrier to seamless communication."

(Kuksa \& Childs, 2014, p. 26)

This brings many limitations, often resulting in students focusing on the first idea that comes to mind, and, using CAD software tools with which they are comfortable, can also create a barrier to communication whilst limiting geometric design freedom. Robertson and Radcliffe (2009) developed four categories of effects resulting from their observations and research into the impact of CAD tools on creative problem-solving in engineering design: enhanced visualisation; premature fixation; circumscribed thinking, and bounded ideation. Their research began with an in-depth case study of one engineering design team (developing an experimental rocket engine). Following this up with a large scale survey to the wider engineering design community $(n=212)$, they discovered that all categories, other than bounded ideation, were common phenomena experienced by engineering designers; these are outlined in Table 1.

Robertson and Radcliffe's study reported on industrial CAD users, with arguably more experience than undergraduates. However, the authors have witnessed first-hand-from a combined six years of teaching- evidence of the categories above with undergraduates and through prior industrial research (Thomas, et al. 2017), along with a number of other barriers to creativity, outlined in Table 2.

\section{The module and the Virtual Reality (VR) intervention}

In order to address the identified creativity gaps the authors decided to focus on the concept generation phase of the engineering design process. Figure 1 shows a simplified version of the engineering design process taught to the students and where we chose to develop the module design (see red dashed outline) to deal with this. Within this module, students were tasked with completing a series of exercises that form the basis of a "major" design, working in groups of six. The module is set up such that students work within their groups to produce designs based on an initial specification. The design process takes them through concept design and iterative design refinement.

In the College of Engineering-at the time of the intervention-Swansea University's Learning, Teaching, and Enhancement Centre (LTEC) was supporting VR technology and implementation into teaching. The authors were able to access and trial a number of VR applications; immediately it was evident that there was clear synergy of this new technology and the early stage of the concept development phase of the engineering design process. Moreover, consultative research with professionals in creativity and innovation training suggests VR technology

Table 1. Impact of CAD tools on creative problem-solving in engineering design adapted from Robertson \& Radcliffe (2009).

Enhanced visualisation \& communication-enhanced ability to visualise and communicate ideas to the team. Does assist creative process as a whole, however, when many are crowded around a monitor, opportunities for brainstorming are limited; furthermore, when a detailed CAD model is displayed, "it can create an illusion of completeness that tends to discourage creative thought in a group situation" (Robertson \& Radcliffe, 2009, p. 137).

Premature fixation-the more detailed the CAD models become during a project, the lower the incentive to make major changes to them; "The models developed a kind of 'inertia' as they become more detailed and concepts become frozen, a phenomenon known as design fixation" (ibid.). In turn leading to a resistance to ideas that could lead to many changes of the model. This may be overcome if all of the creative processes occur at the front of the design effort.

Circumscribed thinking-design ideas and creativity can be limited by the tools in the CAD software (i.e. not possible to replicate a designer's imagination); they are limited by the user's knowledge of the CAD software; moreover, limitations occur because of not only what is possible with a given tool, but what is easiest. Conversely, as proficiency of the CAD user increases over time, design forms grow more complex, and "the design philosophy moved away from one of simplicity and sufficiency and towards one of excellence and even perfection" (ibid.), ultimately leading to unnecessary complexity and wasted time. 
Table 2. Observed barriers to creativity for engineering students (Source: Authors).

\begin{tabular}{|c|c|}
\hline Observed barriers & Consequences \\
\hline Anxiety over the "open" nature of design projects. & $\begin{array}{l}\text { Rush to find existing solutions, rather than problem- } \\
\text { solve and innovate new solutions }\end{array}$ \\
\hline $\begin{array}{l}\text { Lack of spatial awareness, or consideration of realistic } \\
\text { sizes in the design }\end{array}$ & Evidence of design which lacks appropriate scale \\
\hline $\begin{array}{l}\text { Limited information gathering to understand the } \\
\text { use context of the product and the end-users'/ } \\
\text { stakeholders' requirements }\end{array}$ & Limited outcome, lack of user understanding \\
\hline $\begin{array}{l}\text { Difficulty in lateral thinking (i.e. searching alternative } \\
\text { sectors and products for inspiration) }\end{array}$ & $\begin{array}{l}\text { Resultant designs which are similar to existing } \\
\text { products }\end{array}$ \\
\hline $\begin{array}{l}\text { Taking things for granted. Designer bias (i.e. designing } \\
\text { product for someone like themselves) }\end{array}$ & $\begin{array}{l}\text { Lack of empathic design, and understanding of end } \\
\text { user/(s) }\end{array}$ \\
\hline Lack of a human-centred approach & Forgetting who is the end user of the product \\
\hline $\begin{array}{l}\text { Different cultural approaches, which are not in } \\
\text { alignment with a UK-taught approach }\end{array}$ & $\begin{array}{l}\text { When "copying" existing products is considered } \\
\text { acceptable }\end{array}$ \\
\hline $\begin{array}{l}\text { Group dynamics-individuals in groups who do not } \\
\text { engage in the activity }\end{array}$ & Unbalanced individual contribution in the group \\
\hline
\end{tabular}

can facilitate creativity development in a number of ways, such as through guidance or gamification of problemsolving processes, enhancing communication and altering aspects of self-perception which can bring about news ways of thinking (Thornhill-Miller \& Dupont, 2016).

In addition, the authors wanted to understand if VR modelling plays a similar role to that played in science and education as reported, for example, by Mierdel and

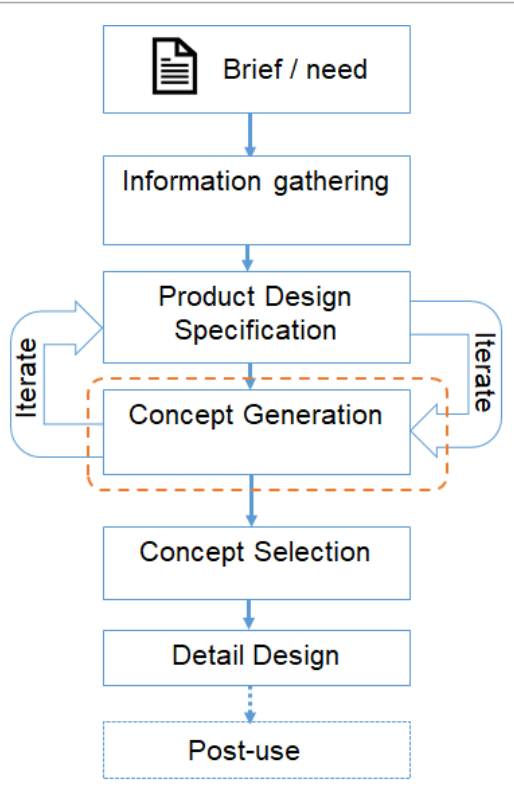

Figure 1. Simplified engineering design process.
Bogner (2019), who describe how modelling plays a key role in comprehension of science research and education; in particular, "...hands-on experiences in authentic learning environments offer students the opportunity to feel like real researchers and support the development of problem-based thinking skills" (Mierdel \& Bogner, 2019, p. 91). The planned use of the VR technology was to allow students to interact with their designs in $3 D$ as part of the concept generation-and to some extent the early embodiment-phases of the design process where embodiment describes the firming up of initial ideas, including the overall layout design, preliminary form designs, production processes and solutions for auxiliary functions (Pahl, Beitz, Feldhusen, \& Grote, 2007). VR is defined as follows:

"... a computer simulation of a real or imaginary system that enables users to perform operations in virtual spaces and shows effects in real time."

(Kuksa \& Childs, 2014, p. 3)

Part of the drive for the authors was to provide undergraduate students with a greater understanding of scale and spatial awareness. Through the use of VR, it is possible to simulate how end users might interact with product concepts in an immersive environment, which it was hypothesised would be highly advantageous for students, who-in the experience of the authorsoften get lost in terms of scale when working on their 
Computer Aided Design (CAD) stations. For example, students would use 10-mm thick steel plate, without thinking about the consequences of weight.

At the time of developing this module, there were only a limited number of VR software options available for concept generation; a number of these were trialled by the authors, and it was found that Gravity Sketch (2019) provided more functionality suited to engineering design than that of other available packages. For example, Gravity Sketch offered the ability to: import and sketch over traditional CAD files; use 1:1 mannequins, and "snap" lines and drawings tools to a scalar grid (assisting in designing to scale). In addition, it was felt that this software would provide a more immersive industrial design experience, relevant to developing engineering concepts. Although still in early development, it provided enough design tools and freedom for our students to develop their creative skills and essentially draw and model in 3 dimensions (3D).

\section{The design brief and introduction of VR into the module}

The Engineering Design module outlined in this paper runs in Semester 2 of a two semester academic year, for 11 weeks. The VR concept development was introduced in weeks 5 and 6 . The VR sessions followed early brainstorming (i.e. concept generation, consideration of stakeholders and end-user requirements), and low fidelity prototyping (i.e. rapid model-making using blue-foam and easily crafted materials, such as cardboard and dowel), but before detail design (see Figure 2). Each group was given 1 hour for initial idea generation, 4 hours for physical prototyping, and 2 hours of VR prototyping. Each session was carried out in project groups, and students were given additional access to the VR software in a communal study area, after the semester break. Objectives and requirements of these sessions were provided in lectures beforehand, along with supporting theory. Furthermore, information was provided on the University's virtual learning platform-i.e. the online platform where module information, course content and additional informationis provided for students. In particular, links to video tutorials and instructions for the preparation of CAD files for import, were included here, to enable students to fully prepare for the sessions.

Careful consideration was made for the design brief, such that it would be open enough to allow the students to have creative freedom, but focused enough to guide them at the start. Furthermore, the brief was developed to allow students capacity to explore a larger design in virtual space, to enable the development of their spatial awareness of a design, where spatial awareness relates to the ability of the student to be aware of objects in relation to oneself in a given space. Of particular importance was the need for the design brief to enable the students to split up their final concepts into individual design

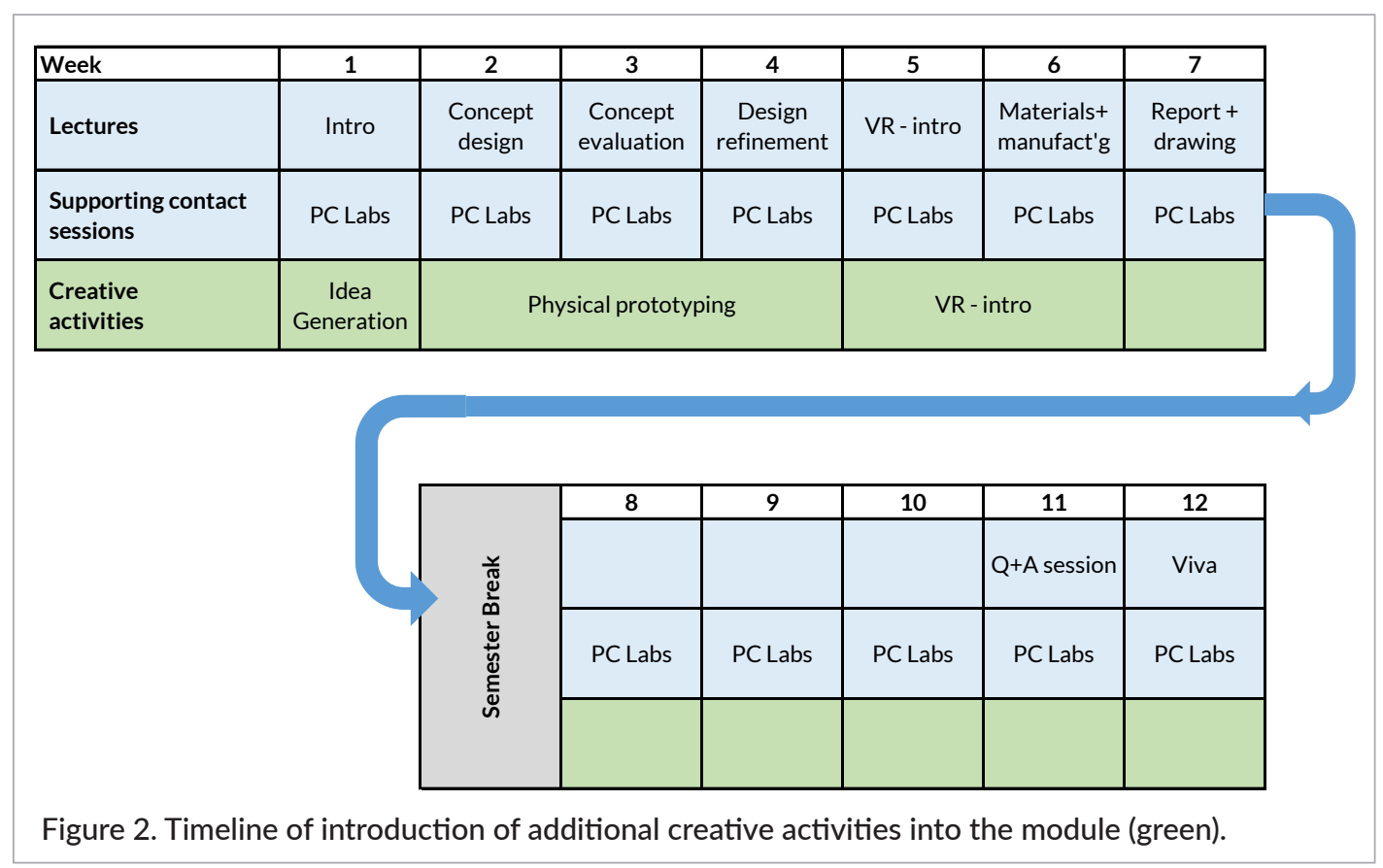


challenges, with appropriate levels of mechanical design. An overview of the design brief is given in Box 1.

When creating this design brief the lecturers were careful to achieve an appropriate level of abstraction of the design problem, a topic which Starkey, Toh, and Miller investigated in their research to understand the relationship between creativity at each stage of the design process. Their results show that the:

"...design task has an impact on creativity throughout

the design process, and identify the importance of task selection in an engineering education...In addition, the results showed that engineering students may be discarding their most novel ideas during the concept selection process in favour of more conventional alternatives."

(Starkey, Toh, \& Miller, 2016, p. 67)

The structure of a design brief consists not only of the design constraints, but also the level of abstraction of these constraints. In the design brief for this intervention, it can be seen that a balance was struck between being abstract on the one hand, or highly constrained on the other; that is, a broad challenge is firstly outlined "The solution you come up with is intended to be humanpowered, by the taxi-driver". This does not specify how the motion of the taxi will be created, leaving a wide scope for human-powered motion. Secondly, "It will need to be able to accommodate two passengers, and their shopping bags/sundries... comfortably over a few miles (up to 5 miles)", which adds essential constraints which can be further established through information gathering by the students, e.g., what is the average weight of an adult in the area of use, what anthropometric data is available for the context of use and so on.
Box 1. Engineering Design Brief-Year 2 Mechanical Engineering Design Module

To design a human-powered taxi for an urban area, such as a city centre (e.g. think of Swansea Wind Street, or Cardiff Central). By thinking and visiting areas like this, it will help you to understand the environment the taxis will need to perform in, e.g. they need to go over cobble-stones, inclines). The solution you come up with is intended to be human-powered, by the taxi-driver. It will need to be able to accommodate two passengers, and their shopping bags/sundries.

The taxi will be suitable for carrying passengers comfortably over a few miles (up to 5 miles), which reflects the short ad-hoc journeys that the driver will make with their passengers.

Working in groups, you will firstly develop a range of overall design concepts. You will then refine these following your workshops and developed product design specification from your research. Following this, each group member will be responsible for a different component. You may choose how you split the design (e.g. chassis, body...).

Each group member must provide a full design of their own part/sub-assembly. Furthermore, all group members must work together to ensure that all parts work together as a complete design.

\section{Practical issues with the integration of VR into a module}

As this paper focuses on the VR aspect of the creative intervention, this section provides further background

Table 3. Issues that needed addressing when implementing VR.

\begin{tabular}{|c|c|}
\hline Deployment issue & Approach/solution \\
\hline $\begin{array}{l}200+\text { students to get through VR experience, with } \\
\text { busy timetables }\end{array}$ & $\begin{array}{l}\text { Students working in groups of } 6 \text { for the design } \\
\text { projects; each group shares a VR setup, taking it in } \\
\text { turns }\end{array}$ \\
\hline $\begin{array}{l}\text { Flat-floor space required, which is in limited supply on } \\
\text { the Campus }\end{array}$ & Close collaboration with timetabling \\
\hline Deployment of VR kit & $\begin{array}{l}1 \text { hour either side of VR sessions to deploy and } \\
\text { pack-up } 9 \text { VR setups }\end{array}$ \\
\hline Support for students during the sessions & $\begin{array}{l}\text { Postgraduate student demonstrators were trained } \\
\text { and used to support the sessions }\end{array}$ \\
\hline Learning curve for students & $\begin{array}{l}\text { Tutorial played in lecture and links to training online } \\
\text { added to the Virtual Learning Environment (VLE) }\end{array}$ \\
\hline
\end{tabular}


on how VR was integrated into the module. It was introduced via an initial lecture which included a short ( 6 minute) tutorial, along with links to further online tutorials for the software, and the online manual. The lecture included a short video as the authors were unsure whether the students would look at the content outside of the lectures, which is often a problem. Furthermore, information was uploaded on the virtual learning platform explaining the aims, objectives and learning outcomes of using $V R$ in the concept phase of the engineering design process. This included detailed information on how the students could export their early CAD models into a suitable format for the VR software, the idea being that students had something they could very quickly bring into the virtual environment and immersive themselves in the context of use, allowing them to interact with the CAD concept(s) and add to it. Whilst one member of the group was immersed in the VR environment, the team members were encouraged to provide feedback and make notes of design improvements, or issues as they arose in real time. There was a great deal of preparation and planning which went into organising these sessions; many deployment issues needed to be overcome before students could use the software, which are outlined in Table 3.

Nine VR setups were deployed per two-hour VR workshop, and 4 sessions in total were carried out. Due to the nature of the setup time of tower PCs, lighthouses (i.e. sensor masts), monitors etc. it was decided that sessions would run back-to-back over two different days (i.e. two sessions per day, and two days in total).

\section{Methods Data gathering}

The authors decided that insight from the actual "users"in this case the students-would provide the most useful insights from this pedagogical intervention. A multipronged data collection approach was taken. A selfcompletion online survey was used to gather data from the undergraduate students before and after the Virtual Reality teaching intervention. The pre-intervention survey was used to:

Establish the level of existing experience and knowledge of the individual student before participating in the creative activities (including VR);

Gain students' perceptions of how these activities assist in the rapid generation and manipulation of ideas;
Rate activities which students have used before in terms of how beneficial they are to problem-solving and creativity;

Understand perception of the CAD training provided in their first year of study;

Gain students' perceptions of how successful they think they will be in using these new creativity tools (i.e. low-fidelity prototyping and virtual reality) in terms of being able to create, modify, manipulate and visualise their concepts; and

- Understand students' enthusiasm for using low-fidelity prototyping and virtual reality.

The post-intervention survey then asked the converse of these questions, for example,

"You have now used virtual reality as part of the concept development process of your design project in [module code]. To what extent are you confident that this method has enabled you to successfully create, modify, manipulate (i.e. move, position) and visualise your concept design using low-fidelity prototyping, on a scale of 1 to 5 ."

This survey was introduced in lectures and also in the first workshop, prior to the students starting the activities. The survey was voluntary, and it was explained that the findings would help develop future design modules. In compensation for their time and as a motivational incentive to complete the survey, students who participated in both the pre and post surveys were entered into a prize draw to win one of five $£ 25$ gift vouchers.

In addition, qualitative data, in the form of responses from mini interviews and a focus group discussion are included for triangulation of results and richness. The study was approved by the University Research Ethics Committee and students provided informed consent to participate.

\section{Sampling method and survey design}

For this project, students undertaking the module were asked to volunteer to take part in the online surveys. The survey was disseminated during lectures, via a shortened URL link (for ease of entry into the URL browser), via announcements on the Virtual Learning Environment (VLE), and before the first workshops began. Questions were also asked during the workshop activities. The postintervention survey URL was also displayed on the TVs around the PC Labs. In the main, the survey used closed questions to make it easier for participants to complete 
in a timely manner, as lengthy and time-consuming surveys can increase the likelihood of biased responses if respondents lose interest or engagement with the task (Teddie \& Tashakkori, 2009). In addition, closed-questions lend themselves well to quantitative analysis and "enhance the comparability of answers, making it easier to show the relationship between variables and to make comparisons between respondents or types of respondents" (Bryman \& Bell, 2011, p. 250). However, restricting response options naturally reduces the scope and spontaneity of responses and removes the opportunity to scrutinise the "why" behind respondents' choices. As such a number of "free-text" questions prompted more detailed answers, to allow respondents the chance to elaborate on their views and thoughts of concept design methods or tools, namely at the end of the surveys. A range of question types was considered when designing the survey depending upon their suitability for the information required. In the main, "informant factual questions" were used (see Bryman \& Bell, 2011, p. 253) which places the participant in the position of informants rather than respondents answering questions about themselves; for example: "to what extent are you confident that this method has helped you to...." with a list of options, rather than "has your confidence increased using this method". Students supplied their student ID only, which could only be cross-referenced with student records by approved staff. However, the only need for the ID was to cross-reference participants who had completed both surveys.

\section{Additional data collection}

In addition to the survey, in mini interviews, students were asked to answer brief questions whilst carrying out the creative activities, and their responses were recorded on a dictaphone and then later transcribed. Once the module had completed, a number of students volunteered to take part in a focus group discussing the changes to the module, again this was recorded and transcribed. An example of the questions asked during the $\mathrm{VR}$ sessions can be seen in Box 2 .

\section{Results}

There were 77 responses to the pre-intervention survey and 58 responses to the post-intervention survey. In total, 36 students completed both surveys, which represents $18 \%$ of the total cohort. 190 students also completed mini interviews during the VR sessions and 6 students took part in the post-intervention focus group.

\section{Survey results}

The responses of the pre-intervention survey were compared with post-intervention results, in addition to responses from those participants who had "no prior experience of using VR". Data from the pre- and postintervention surveys were compared using a t-test to check for statistical difference between the datasets. For this test, a value of "1" was assigned to the lowest response for each question ("major barrier" or "most difficult"), increasing to a value of "5" for the most positive response ("major enabler" or "easy to use and intuitive"). For the question about rating the usefulness of CAD in terms of problem-solving, a paired (correlated) $t$-test was used because there was an equal number of pre- and post-intervention responses. For subsequent questions, the pre-intervention survey was only completed by those who indicated that they had prior VR experience. The post-intervention responses were then split between all participants and those without prior $V R$ experience. Due to the difference in sample sizes, the two-sample unequal variance (heteroscedastic) t-test was used to determine the statistical significance of these responses. The probabilities of the responses being statistically

\section{Box 2. Example of questions asked during VR sessions}

1. Tell us your thoughts about this virtual prototyping session: e.g.

a How easy has it been to learn and use the VR software?

b Did you look at the online tutorials before this session? Did they help?

c Do you find prototyping using this VR software easy or difficult to generate and develop your ideas?

d Why?

e Has this process increased your ability to problem-solve and generate novel solutions?

f How/ why?

g How has this process helped (or otherwise) your ability to visualise your concept designs?

h How has this process helped you to change your ideas or focus on new ones?

2. Any other thoughts? 
similar were obtained by calculating the corresponding $p$-values from the $t$-tests and comparing these to a level or significance taken as $a=0.05$.

Using CAD and VR for problem-solving: For the question "Rate how useful CAD was in terms of problem-solving", no students identified it as either a major barrier or somewhat of a barrier before the intervention (Figure 3). However, after the intervention, 7 students identified it as either a major barrier or somewhat of a barrier, representing about $20 \%$ of the total responses. The number of students who considered CAD as either an enabler or major enabler of problem-solving decreased from $91 \%$ to $69 \%$ of respondents after the intervention. These results are corroborated by responses from the mini interviews and discussion during the focus group, which will be summarised in the next section. The mean responses for the pre- and post-intervention are 4.36 and 3.77 , respectively. The standard deviation of the responses increased from 0.64 before the intervention to 1.29 after, indicating less consensus in the postintervention responses. The $p$-value calculated using the paired t-test is 0.0001 , which is less than a, giving confidence that the difference in responses is significant.

The number of students who thought that VR was useful for problem-solving increased after the intervention; however, 16 out of the 36 participants who completed both surveys had not used VR before. Of these 16 students, 14 identified VR as either an enabler or major enabler to helping them problem-solve. Of the
36 participants, 6 identified VR as a barrier or major barrier to helping problem-solve (see Figure 4). The mean response for this question pre-intervention is 4.00 which is similar to the post-intervention mean of 4.03 and mean response from those without prior $V R$ experience of 4.25. Comparing the responses of the post-intervention with the pre-intervention responses using the unequal variance t-test yields a $p$-value of 0.94 , indicating no significant difference between the datasets. Applying the same comparison to the survey responses from those with no prior $V R$ experience gives a $p$-value of 0.26 . This value, although lower than the $p$-value obtained when comparing all post-intervention responses, is still greater than the significance level, $a$, and therefore it cannot be concluded that there is any difference between the responses before and after the intervention.

Creating concept designs in VR: In response to the question about the ease of creating concept designs in $\mathrm{VR}$, a majority of respondents stated that it was average to use (Figure 5). Taking a mean score of answers from the survey prior to the intervention, a value of 3.20 is obtained compared to 3.44 after the intervention, meaning that the general consensus is that the software is just easier than average to use. For those who had not used VR before, the mean score was 3.38. No respondents listed $V R$ as being very difficult to create concept designs. Applying the t-test to the pre- and postintervention responses for all students yields a $p$-value of 0.39. Comparing the pre-intervention responses to the

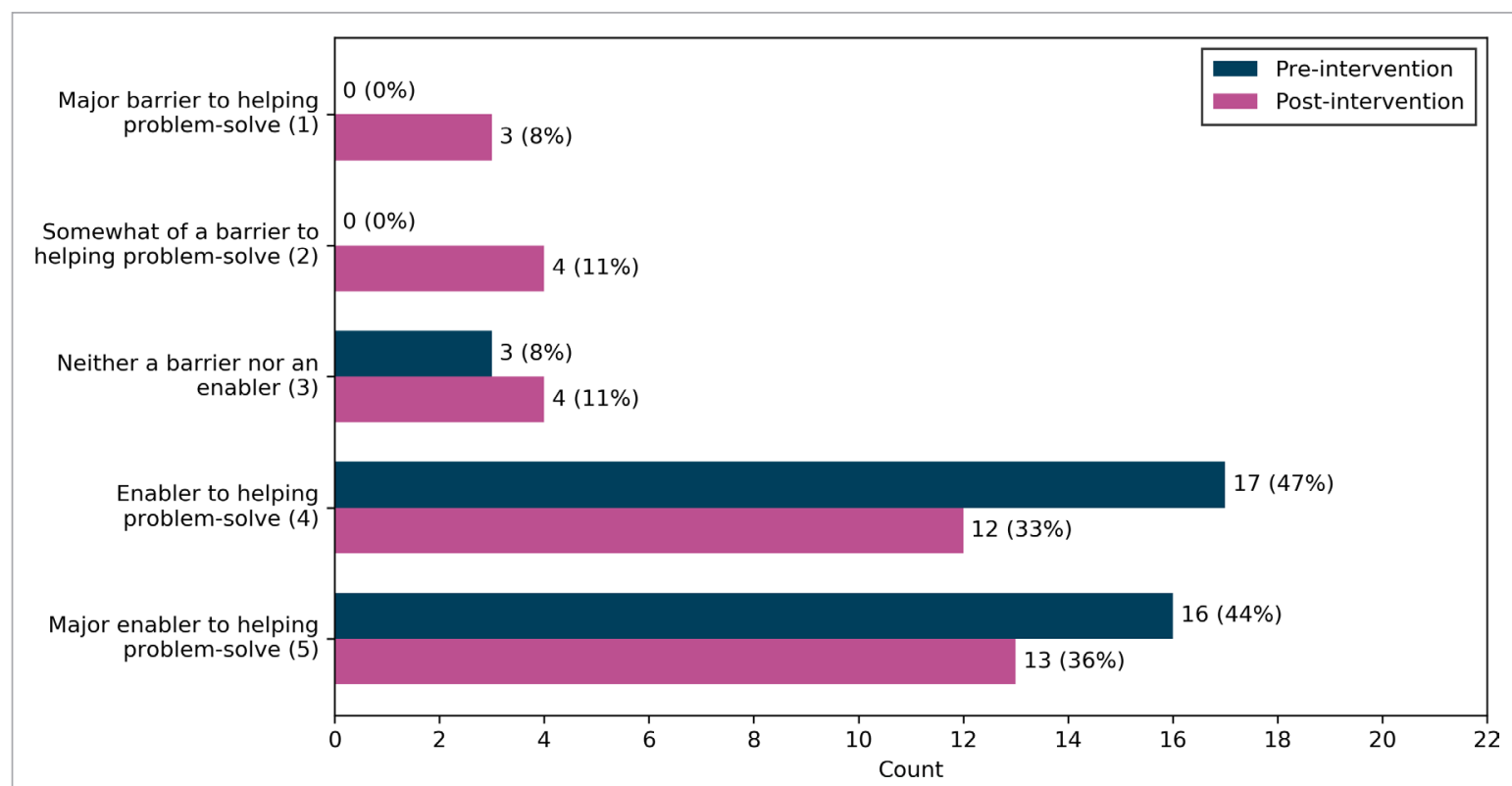

Figure 3. Students' perceived usefulness of CAD for problem-solving, before and after the intervention. 


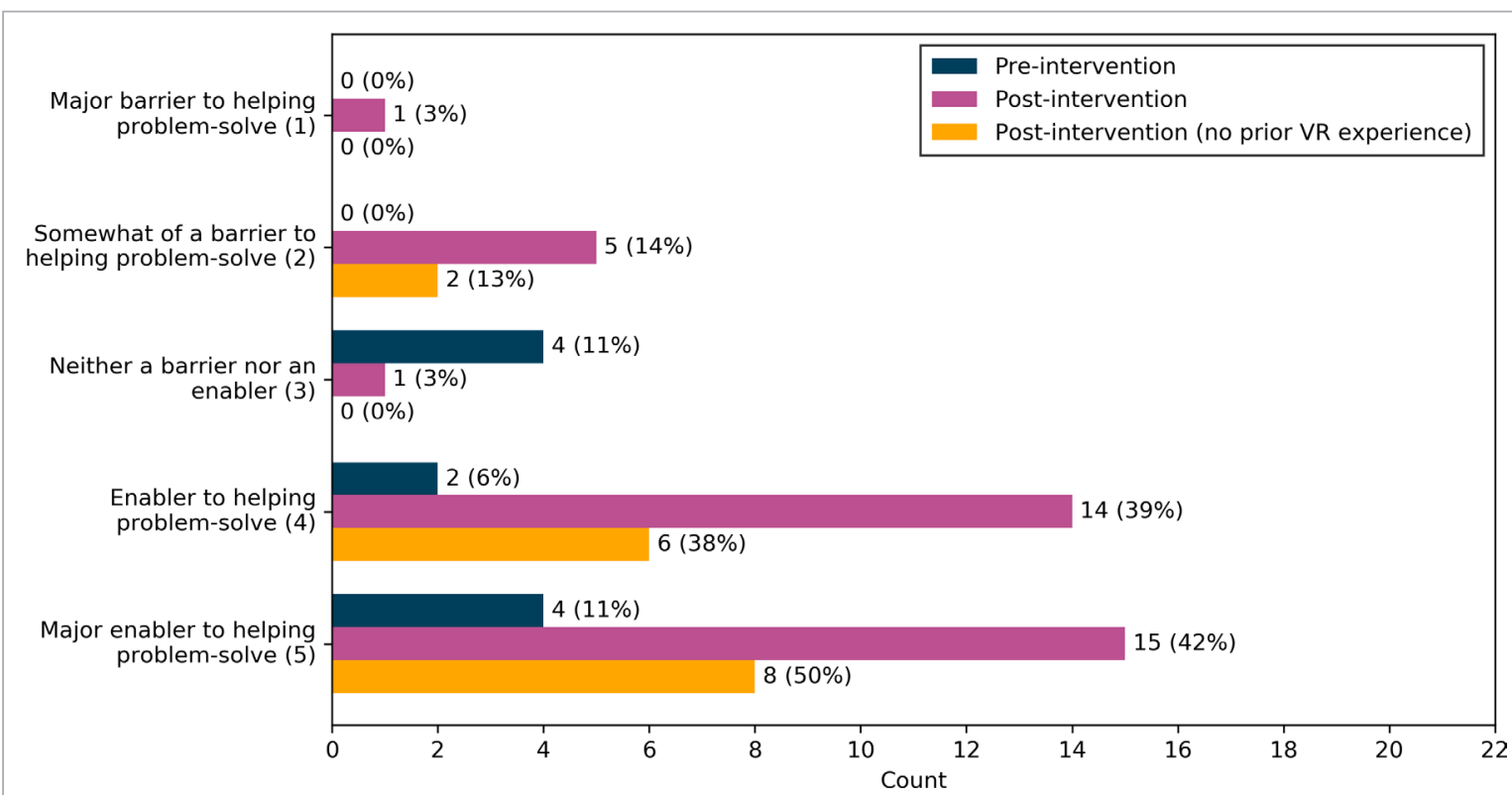

Figure 4. Students' perceived usefulness of VR in terms of problem-solving, before and after the intervention.

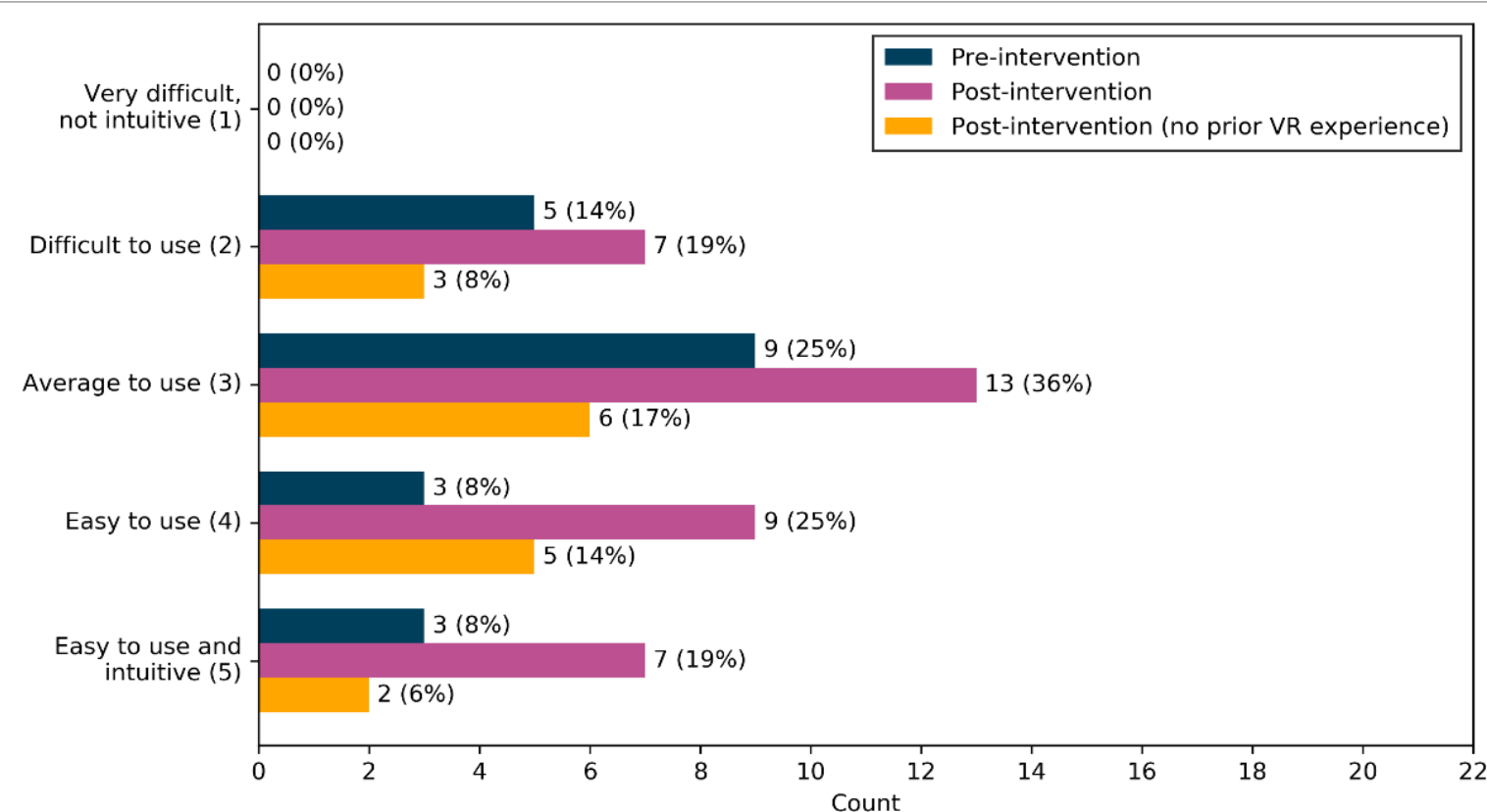

Figure 5. Students' perceived ease of creating concept designs using virtual reality, before and after the intervention.

post-intervention responses from those without prior VR experience gives a $p$-value 0.60. Both of these values are significantly greater than the significance value, therefore there is no change in perceived difficulty in creating concept designs pre- and post-intervention.

Modifying concept designs in VR: Prior to the intervention the most frequent response to the question about the ease of modifying concept designs using VR was that it was average to use, with 10 out of 36 participants (27\%) selecting this option. After the intervention the most frequent answer was that it is easy to modify designs, using VR with 15 participants (42\%) identifying this. The number of respondents identifying VR as being easy to use and intuitive when modifying designs increased 


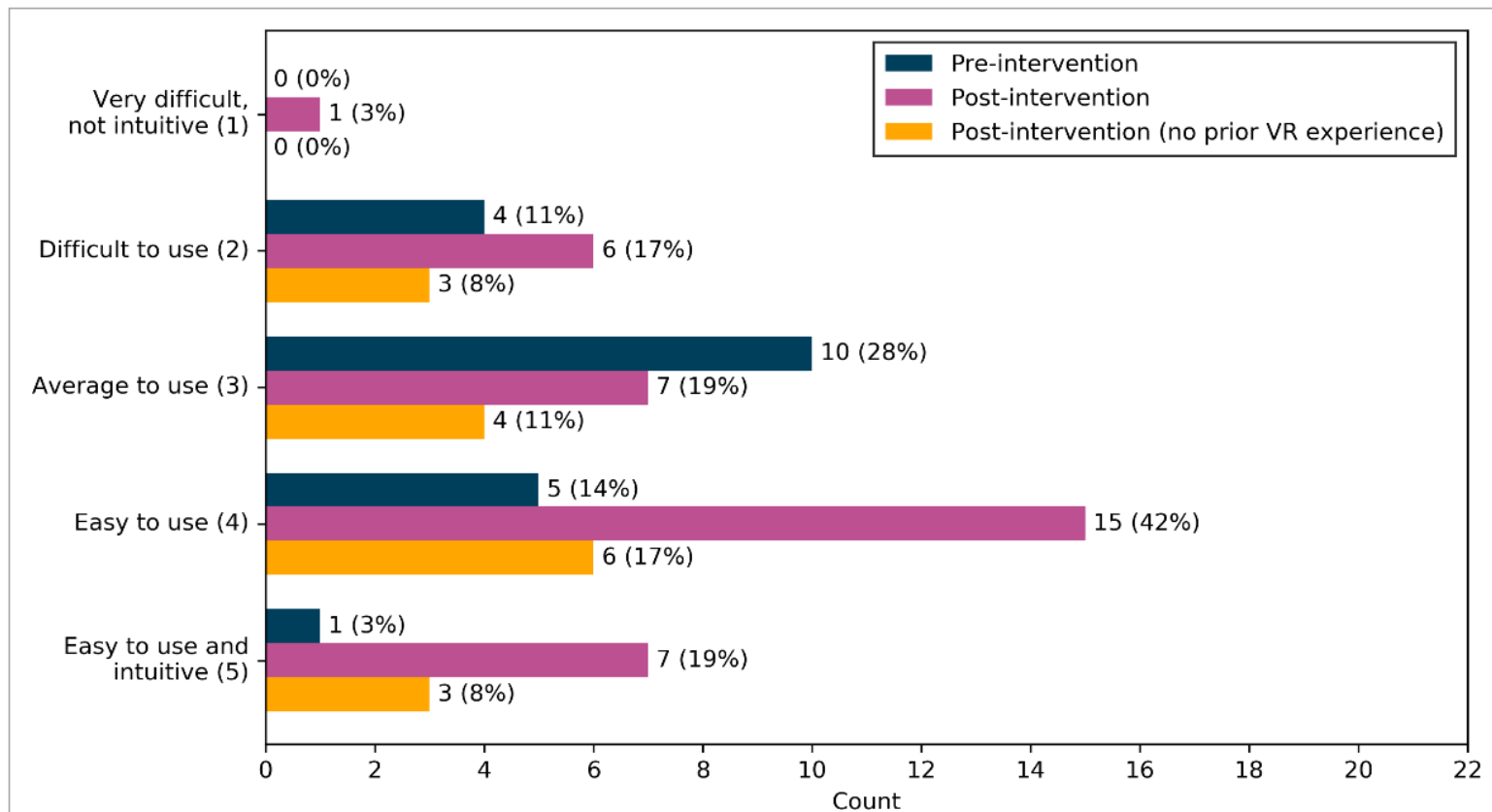

Figure 6. Students' perceived ease of modifying concept designs using virtual reality, before and after the intervention.

from 1 to 7 after the intervention (see Figure 6). The mean response for this question increased from 3.15 pre-intervention to 3.58 afterwards (3.56 for those without prior $V R$ experience). However, the standard deviations of the post-intervention responses was $>1.0$ meaning that there was a broad range of responses (see Figure 6). Applying the $t$-test to this dataset yields $p$-values of 0.12 for all the post-intervention response and 0.19 for those without prior VR experience; both values are greater than $a$. Although there appears to be a shift towards a more positive perceived ease of modifying concept designs after the intervention, this is not significant.

Manipulating concept designs in VR: From the results of the survey question about how easy it is to manipulate concept designs using VR, $42 \%$ of participants who had used $\mathrm{VR}$ before considered it to be average to use before the intervention (Figure 7). This reduced to $14 \%$ after the intervention with $81 \%$ of respondents considering VR easy to use or easy to use and intuitive. No participants considered VR very difficult to manipulate their concept designs before or after the intervention and the number of respondents who considered it difficult decreased from 3 to 2 (see Figure 7). The mean score for this response before the intervention was 3.58. Post-intervention, this increased to 4.14 (4.31 for those without prior VR experience). Low $p$-values were obtained from the t-test: $9.33 \times 10^{-6}$ and 0.04 for those with and without prior $V R$ experience respectively, indicating confidence in the improved perceived ease of modifying concept designs using $V R$.

Visualising concept designs in VR: From answers to the question about how easy it is to visualise concept designs in VR, $94 \%$ of participants listed visualising concept designs as easy or easy and intuitive in the follow-up survey, increasing from $28 \%$ in the pre-intervention survey (Figure 8). The mean response increased from 3.55 to 4.44 after the intervention. For those without prior $V R$ experience, the mean response increases to 4.56, indicating that $V R$ was much easier and intuitive to use than expected. The $p$-values obtained from the $t$-test for each of these datasets were 0.0019 and 0.0042 giving confidence in these responses.

From the survey results, it can be seen that students' perceived usefulness of CAD in terms of problem-solving for design decreased after having used VR for developing concept designs. Also, students found that modifying, manipulating and visualising concept designs using VR was easier than expected prior to the intervention. There was no change in the perceived ease of use and usefulness pre- and post-intervention. Some more insight into the responses can be gained by looking at the responses to the mini interviews that took place during the VR sessions. 


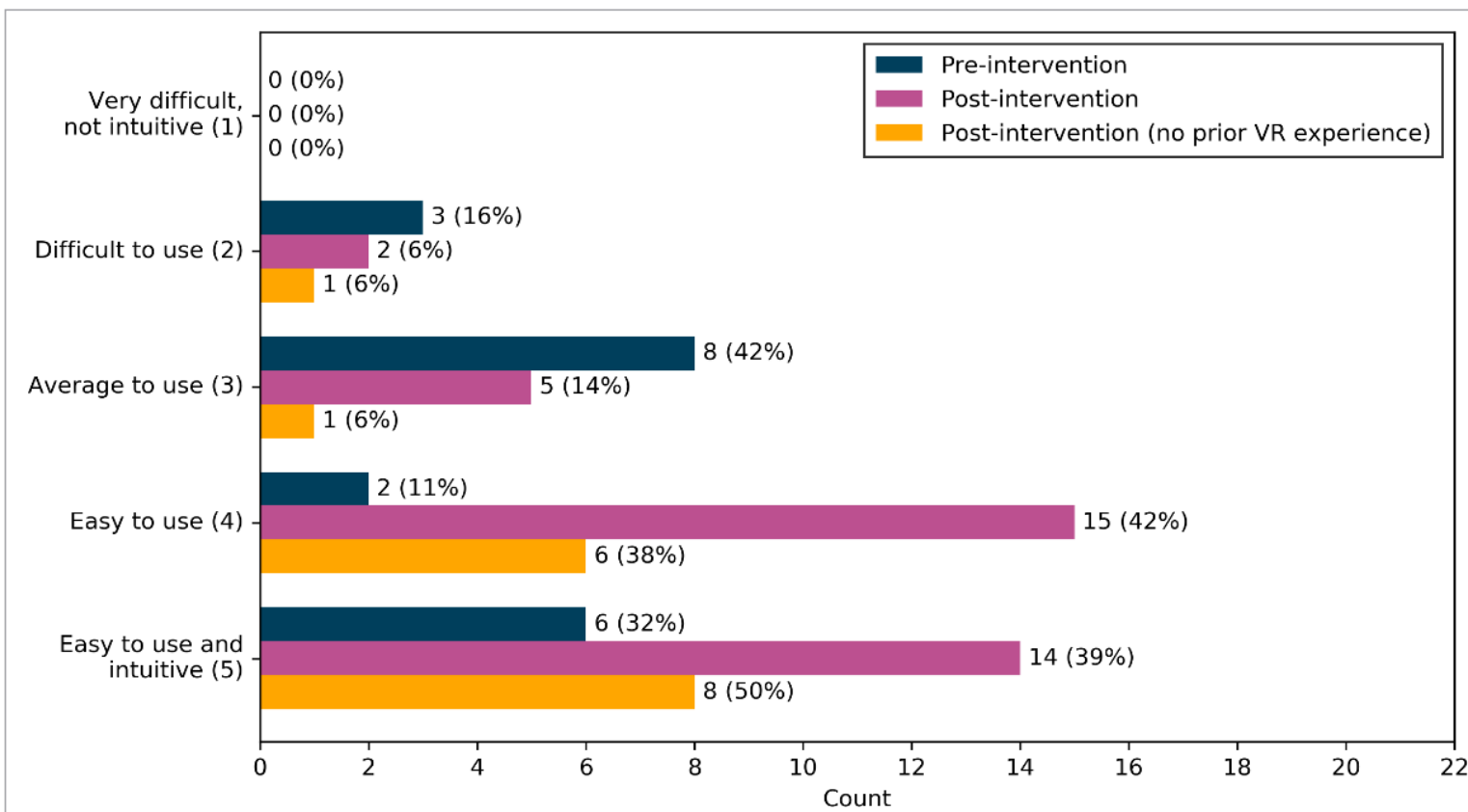

Figure 7. Students' perceived ease of manipulating concept designs using virtual reality, before and after the intervention.

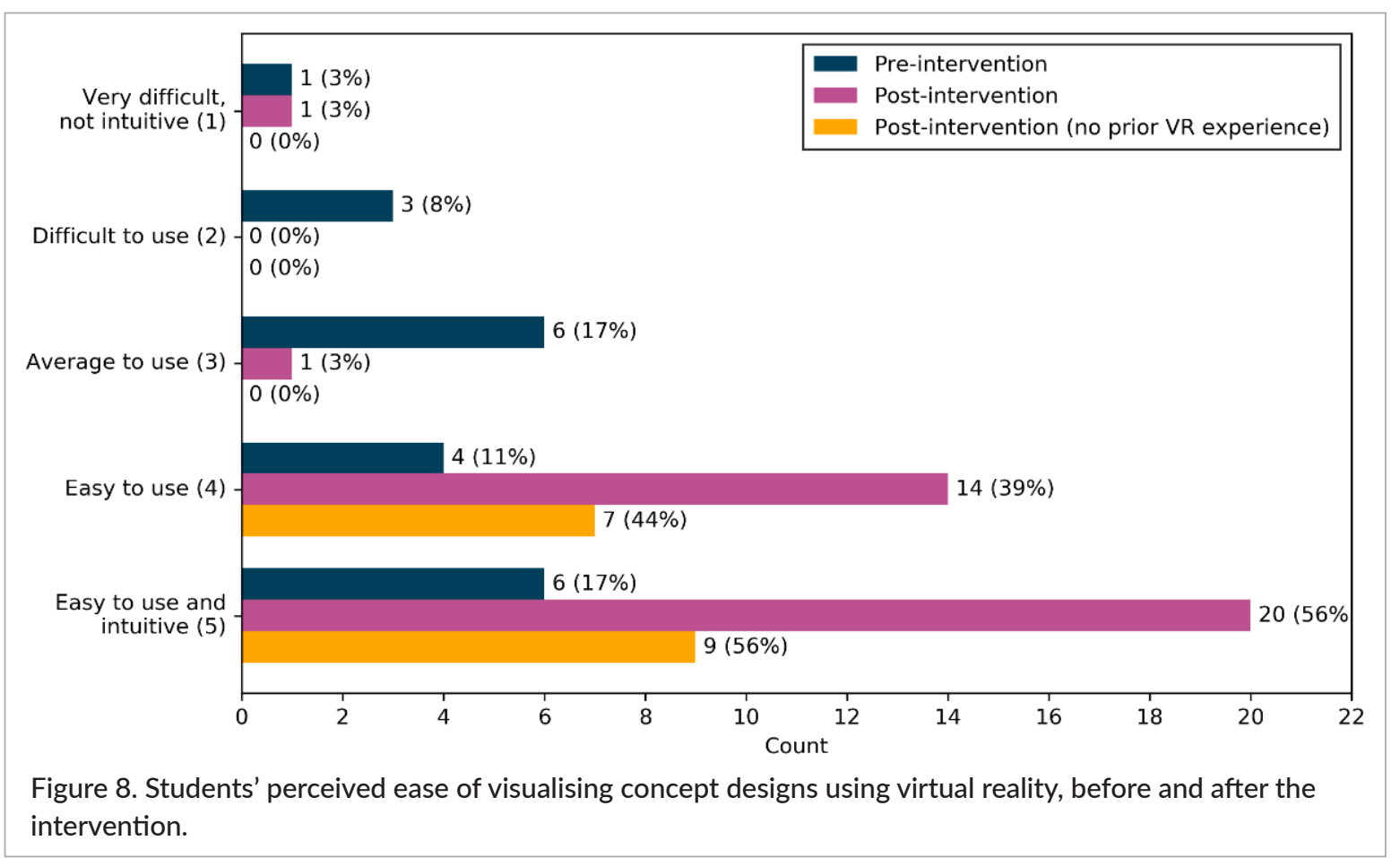

\section{Interview results}

Using CAD and VR for problem-solving: Once the initial learning curve of using the VR software for immersive 3D design was overcome, students reported that it was easy to use the software to develop their ideas without the restrictions resulting from standard CAD.
One student said that VR was:

"Initially tricky to get [my] head around... after hour or so get proficient at it. Didn't look at online tutorials before! Probably would have helped. It is easy once proficient with software; can put things in place quicker than in SW [SolidWorks CAD package]." 
Another student described how they were able to "pick it up quite quickly" and how:

"It's quite cool actually, just a good chance to get in and have a play with something different/another way of looking at. Quite easy to use... especially easier than CAD because with CAD you've got to mess around with everything when you change something... but with this it's as easy as drag and drop."

This emphasised the ease of with which ideas could be generated, however the same student also said that they would "stick to CAD but if [they had] more practice with this [it] would make problem-solving a lot easier", which ties in with other comments about wanting to have longer sessions using the VR software to use its full functionality. Suggestions for additional VR access outside of planned workshops were put forward by some students as a way to address this. One student did describe that VR did not increase problem-solving for them, but "...helped visualise ideas".

Creating and visualising concept designs in VR: During their VR session, one student described how VR was, "quite easy to pick up; in terms of creating content on it... [however, it] wouldn't be used on its own, good used in conjunction with other CAD", highlighting the need to move on to CAD during the embodiment design stage, as the level of detail of the design increases, and that it was "...quite hard to create specific designs with the [VR] drawing".

In terms of developing concepts as a group, one participant highlighted how it would be beneficial for a group proficient in the software:

"Overall, I think it's a really good method of doing it and I did think if perhaps you had your whole group proficient in how to use the software and you are all in the workspace together you could design a project really rapidly as can do in workspace. Rather than talking through, less efficient than drawing in VR."

However, a number of students did point out that the lack of dimensions or quantitative data could be problematic:

"I didn't found it very helpful. I still prefer SW, because can do measurements and join together. Prefer SW as dimensions. This software just make the shape, I have no idea of what the dimensions."

Modifying concept designs in VR: Comments from students included: "Quite easy to use... especially easier than CAD because with CAD you've got to mess around with everything when you change something, but with this it's as easy as drag and drop", and, "It is easy once proficient with software; can put things in place quicker than in SW".

Additional positive comments were: "The software was really intuitive; feel involved; could spend hours in there", and, "Easy to generate ideas with. Instantly create ideas in 3D".

Although, when it came to specificity of the concept designs, it was noted that it is: "Quite hard to create specific designs with the drawing. In terms of making notes and seeing it almost physically, virtually really helped with dimensions", and, "VR is very engaging. Has helped us point out some of the mistakes I made in the design, so overall I like the fact that I've come here, because now I know what to tackle next".

Manipulating concept designs in VR: Here, one student commented that, "In terms of making notes and seeing it almost physically, virtually, really helped with dimensions".

\section{The design brief}

Students were asked in the focus group: "What about the actual design brief because it was a human powered taxi, what do you think about that?". The following responses were given: "I think it was quite interesting actually, like it was vague enough to like have a lot of creative ideas but specific enough that you know what you need to do..."; "This year is more mechanical, whereas I think there's another design module for Medical which is like a robot arm, it's nice the fact that they've tailored it to us", and, "It made me appreciate it more because it's like they thought about the module rather than just did it, [in the first year] it was more generic like we'll just give them the [previous] one again".

These comments appear to suggest that the project brief presented the right balance for this intervention. The analysis of students' experiences in relation to Robertson and Radcliffe's (2009) categories: enhanced visualisation; premature fixation; circumscribed thinking, and, bounded ideation, is illustrated with examples in Table 4.

\section{Employability}

Students were also asked in the focus groups whether learning the VR during this module was something that would help them from an employability perspective. The following responses were given:

So I feel like it's definitely been useful because we can say we did VR at Uni

It preps us

Like before going into industry, not having any idea how to use it would be like far worse 
It's just nice to know that you've used it as well. Even if it's a different software we're using, to get used to how it works... Thus, through such exposure to these technologies, pedagogical interventions such as this are training the future engineers to be more creative.

\section{Discussion and conclusions}

The aim of using VR to help teach Mechanical Engineering design was to enhance opportunities for creative thinking and innovation and problem-solving. The results of the study show that after introducing $V R$, the number of

Table 4. Participant data (direct quotes) showing how this VR intervention addresses Robertson and Radcliffe's (2009) effects of CAD tools on creative problem-solving in engineering design.

\begin{tabular}{|c|c|}
\hline \# & $\begin{array}{l}\text { Enhanced visualisation \& communication-Enhanced ability to visualise and communicate ideas to a } \\
\text { team. Overcoming the illusion of a completed design that a detailed CAD model presents when dis- } \\
\text { played. }\end{array}$ \\
\hline a & The software was really intuitive; feel involved; could spend hours in there. \\
\hline$b$ & $\begin{array}{l}\text { Overall, I think it's a really good method of doing it and I did think if perhaps you had your whole group proficient } \\
\text { in how to use the software and you are all in the workspace together you could design a project really rapidly as } \\
\text { can do in workspace. Rather than talking through, less efficient than drawing in VR. } \\
\text { Another participant explained how when group members swapped over to using the VR, they had to } \\
\text { spend time understanding the controls first and getting on with their parts... rather than interacting with } \\
\text { their teammates: you couldn't really bounce of each other that much as you were trying so hard to focus on the } \\
\text { controls... }\end{array}$ \\
\hline C & $\begin{array}{l}\text { I felt like it was different actually seeing it in VR to seeing it on the screen because when you're in the VR you } \\
\text { know what's going on and what you don't do. With the screen you're kind of watching, it's kind of hard to visualize } \\
\text { what the person with the VR is actually seeing. } \\
\text { This reflects the barrier of a screen to communication (Kuksa \& Childs, 2014). }\end{array}$ \\
\hline d & $\begin{array}{l}\text { Yes, it was overwhelming at first because there were so many controls and I didn't know what did what. But after } \\
\text { a while you got used to it and knew what you were doing. You could like move things, make things bigger, add } \\
\text { colour, so it was pretty easy to use in the end... By the end of it I wanted more time, by the end of the session I felt } \\
\text { like I was just properly getting into it. It was a shame we only had an hour but it was nice to experience it. }\end{array}$ \\
\hline e & $\begin{array}{l}\text {...so scale is such an important thing and SolidWorks just doesn't give you that sense of scale really. Yeah... But } \\
\text { the VR definitely did. }\end{array}$ \\
\hline & $\begin{array}{l}\text { Premature fixation-the more detailed CAD models become during the project, the lower the incentive to } \\
\text { make major changes to them. }\end{array}$ \\
\hline f & $\begin{array}{l}\text { Quite hard to create specific designs with the drawing. In terms of making notes and seeing it almost } \\
\text { physically, virtually really helped with dimensions. }\end{array}$ \\
\hline & $\begin{array}{l}\text { Circumscribed thinking-ideas and creativity limited by tools in CAD software (not possible to replicate } \\
\text { designer's imagination). }\end{array}$ \\
\hline g & Easy to generate ideas with. Instantly create ideas in 3D. \\
\hline $\mathrm{h}$ & It is easy once proficient with software; can put things in place quicker than in SW. \\
\hline i & $\begin{array}{l}\text { [this group imported a template model into VR] } \\
\text { We created it as a group and then we drew on all the intricate parts and curves; it was easiest for us to do } \\
\text { because on CAD it would have taken a long time. } \\
\text { We sat a chair as well inside the like space so you could physically sit in your taxi and like design around you. It } \\
\text { was really cool because it made you think more about what you'd need whilst sat in the taxi. And also they have } \\
\text { like scale people that you could like add in so you could physically see where legs would go and arms would go } \\
\text { and how they sit in the taxi which is good. } \\
\text {... we realized our seat was really low down, there was no leg room at all... }\end{array}$ \\
\hline
\end{tabular}


students who considered traditional CAD as an enabler for creativity reduced. Moreover, following the $V R$ intervention over $80 \%$ of participants considered $V R$ as an enabler or major enabler in-terms of problem-solving.

A majority of students who used Gravity Sketch to help them develop their concept designs found it easy to use after an initial steep learning curve. This highlights the importance of incorporating appropriate training and orientation with the software into the learning experience, to allow students to effectively utilise and thus benefit from this approach. Nevertheless, those who had not used VR before, generally found it average or easy to use, and participants stated that they enjoyed the VR sessions and that they found them useful to visualise their concept designs.

Together, these findings suggest that VR could be an effective methodology for supporting problem-solving activities and visualisation of design concepts in an undergraduate engineering design module

In relation to Robertson and Radcliffe's (2009) categories: enhanced visualisation; premature fixation; circumscribed thinking, and, bounded ideation (see Table 4 ), the following observations are made from this study:

\section{Enhanced visualisation and communication:}

- A future improvement would be to have all of the group members in the same virtual workspace, plus increased training on the software. This is a feature the software producers are currently exploring;

-The screen displaying the VR view of a team member created a potential barrier for those not in VR. This agrees with Kuksa and Childs' (2014) observation that screens are a barrier to communication;

-Additional time to "learn" the software would be beneficial, and,

Additional "drop-in" sessions for students to learn the software would be beneficial.

\section{Premature fixation-the more detailed CAD models become during project, the lower the incentive to make major changes to them:}

$\checkmark R$ removes the ability to be too specific early on, which may help to prevent premature fixation.

\section{Circumscribed thinking-ideas and creativity limited by tools in CAD software (not possible to replicate designer's imagination):}

The ability to immerse oneself in the design clearly helped the students here, and,
They also noted that there was an issue with scale though, as although parts were relative in size, there was no way of checking: "... when you put the people in, there's no dimensions next to them so when you make them smaller and bigger you have no idea how big they are. It's weird to see a person you'd just scale it to the taxi but we had no idea what the scale of the taxi was".

In terms of how the affordances of VR differ from traditional CAD tools, the qualitative data suggests that VR makes it more difficult to be too specific early on in the design process. This may reduce the potential for "Circumscribed thinking", which Robertson and Radcliffe (2009) identified as an obstacle to creative problemsolving using CAD software tools, as users' imaginations are often restricted from the beginning by the functions and parameters of CAD which inherently narrows the creative options available. It is possible that the design parameters are less circumscribed or formulaic in VR design software, which allows students to generate and explore a greater range of ideas early on from which to choose their final design.

Moreover, the enhanced ability to visualise concepts in $V R$ reported by the students may support creative problem-solving if they are able to explore the full design for themselves privately in VR. Difficulties with visualisation, such as having to crowd around a CAD model on a 2D screen, were identified by Robertson and Radcliffe (2009) as an obstacle to creative problemsolving, which VR design software may overcome. Furthermore, some students described how designing in VR allowed them a better understanding of the spatial properties of their designs in a three-dimensional space. A key "observed barrier" to creativity initially identified by the authors, was that students using traditional CAD software often demonstrate a lack of spatial awareness or understanding of realistic proportions in their designs. Therefore, VR appears to offer some benefits at least qualitatively for students to appreciate and understand the spatial properties of their designs in a more concrete way, which would not be possible with traditional flatscreen CAD software.

However, in line with Kuksa and Child's (2014) observation that screens in general can be an obstacle for effective communication, some students did report that watching their peers in VR on a 2D screen brings the familiar barriers to communication as experienced in traditional CAD software. Robertson and Radcliffe (2009) highlighted that CAD software provides limited 
opportunities for brainstorming which can inhibit creative problem-solving. This may also be a problem using VR design software, if it is only accessible to one group member at a time. There is some evidence to suggest that a group-based VR design methodology, may overcome some of the communication problems associated with the isolated VR-user in team tasks, by facilitating cooperative idea generation among students (Thorsteinsson, Page, \& Niculescu, 2010) and could be explored in future research.

A considerable amount of resource-planning and administration (e.g. adding long sessions into busy timetables, finding rooms with large flat floor spaces) was required to set this new learning experience up, which must be considered for anyone contemplating this approach. Having dedicated VR Research Officers and Technicians for setting up the VR hardware was essential, along with Postgraduate students who were trained in the software to act as additional demonstrators was also required. It was also important to have contingency plans for when machines crashed or went down.

\section{Implications for future teaching practice}

The findings from the intervention are promising when considering the nascent nature of these technologies. At the time of writing, this engineering design module is being conducted for the second time with virtual reality and associated creative engineering design activities. Building on feedback from this initial intervention the authors have made the following changes for subsequent delivery of the module:

An additional VR training session;

- Introducing VR earlier in the engineering design process (i.e. group project);

VR café-i.e. additional VR day sessions once per week where students can drop in and develop their designs, and,

A focused introductory video on how to use the software, developed by the software providers for this module.

Previous authors have highlighted the importance of work in this area, suggesting that our study makes a valuable contribution:

"If developing innovative engineers is a goal of engineering education, then creativity shouldn't be relegated to some first year engineering design course and a capstone course. It should be in everything. Engineering courses which ask students to simply apply theory covered to a rote problem that all students do is a wasted opportunity, both for learning better how to apply the theory and for nurturing growth in creativity and innovativeness" (LaDuca, 2017, p. 55).

\section{Future research}

The authors would like to measure the creative outputs in future research, using a similar approach to Starkey et al. (2016) which would involve asking impartial reviewers (ideally with industrial engineering design experience) to rank the students' solutions. Of particular interest would be the comparison of initial concepts presented during the stage 1 concept Vivas (i.e. oral exams where students are assessed on their presentation of initial ideas), in comparison with the stage 2 detailed design Vivas (i.e. oral exams where students present their final detailed designs along with their accompanying reports).

\section{Acknowledgements}

The authors would like to thank Gravity Sketch for their technical support in the use of their software. Furthermore, the authors would like to thank the University VR technicians who were fundamental in setting up and supporting the equipment for the student VR sessions, along with the demonstrators, and of course the students who were willing to try this new approach to concept generation.

\section{References}

Amabile, T.M. (1988). A model of creativity and innovation in organizations. Research in Organizational Behaviour, 10(1), 123-167.

Bryman, A., \& Bell, E. (2011). Business Research Methods (3rd ed.). Oxford: Oxford University Press.

Cropley, D.H. (2015). Creativity in Engineering. Oxford: Oxford University Press.

Edwards-Schachter, M., Garcia-Granero, A., SanchezBarrioluengo, M., Quesada-Pineda, H., \& Amara, N. (2015). Disentangling competences: Interrelationships on creativity, innovation and entrepreneurship. Thinking Skills and Creativity, 16, 27-39. 
Gravity Sketch. (2019). Retrieved from Gravity Sketch

Web site: https://www.gravitysketch.com/

Henriksen, D., Richardson, C., \& Mehta, R. (2017).

Design thinking: A creative approach to educational problems of practice. Thinking Skills and Creativity, 26, 140-153.

Herrmann, N. (1991). The creative brain. The Journal of Creative Behaviour, 25(4), 275-295.

Institution of Mechanical Engineers. (2019). Retrieved 2019, from Institution of Mechanical Engineers Web site: http://www.imeche.org/

Joao, I.M., \& Silva, J.M. (2014). Concept mapping and mind mapping to lift the thinking skills of chemical engineering students. International Journal of Engineering Pedagogy, 4(5), 42-48.

Kuksa, I., \& Childs, M. (2014). Making Sense of Space. The Design and Experience of Virtual Spaces as a Tool for Communication. UK: Chandos Publishing (Elsevier).

Mierdel, J., \& Bogner, F.X. (2019). Is creativity, hands-on modeling and cognitive learning gender dependent? Thinking Skills and Creativity, 31, 91-102.

Morin, S., Robert, J., \& Gabora, L. (2018). How to train future engineers to be more creative? An educative experience. Thinking Skills and Creativity, 28, $150-$ 166.

Pahl, G., Beitz, W., Feldhusen, J., \& Grote, K.H. (2007). Embodiment design. In G. Pahl, W. Beitz, J. Feldhusen,
\& K.H. Grote (Eds.), Engineering Design (pp. 227-436). London: Springer.

Plucker, J.A., Beghetto, R.A., \& Dow, G.T. (2004). Why isn't creativity more important to Educational Psychologists? Potentials, pitfalls, and future directions in creativity research. Educational Psychologies, 39(2), 83-96.

Robertson, B.F., \& Radcliffe, D.F. (2009). Impact of CAD tools on creative problem-solving in engineering design. Computer-Aided Design, 41, 136-146.

Starkey, E., Toh, C.A., \& Miller, S.R. (2016). Abandoning creativity: The evolution of creative ideas in engineering design course projects. Design Studies, 47, 47-72.

Teddie, C., \& Tashakkori, A. (2009). Mixed Methods Research, Integrating Quantitative and Qualitative Approaches in the Social and Behavioural Sciences. London: Sage.

Thomas, A., Dorrington, P., Costa, F., Loudon, G., Francis, M., \& Fisher, R. (2017). Organisational learning capability in SMEs: An empirical development of innovation in the supply chain. Cogent Business and Management, 4(1).

Thorsteinsson, G., Page, T., \& Niculescu, A. (2010). Using virtual reality for developing design communication. Studies in Informatics and Control, 19(1), 93-106. 